\section{Deletion (2)(p14p15) in a child with severe neurodevelopmental delay}

EDITOR-Cases with pure short arm deletion of chromosome 2 are rare. Among these cases chromosomal deletions within the region $2 \mathrm{p} 21$ to $2 \mathrm{p} 23$ have been associated with holoprosencephaly. ${ }^{1-3}$ Five cases with multiple anomalies, including microcephaly, have been reported to have more distal deletions within the region 2 p23 to 2 pter. $^{4-7}$ Four cases have been reported with more proximal deletions involving segments 2p11-p21, 2 p13-p15, ${ }^{8}$ 2p11-p13, ${ }^{10}$ and $2 \mathrm{p} 11.2-\mathrm{p} 13 .{ }^{11}$ Patients in these cases were dysmorphic with psychomotor retardation. Wenger and McPherson ${ }^{12}$ reported a fifth case of a dysmorphic infant with $\operatorname{del}(2)(\mathrm{p} 11.2 \mathrm{p} 13)$ who died at the age of 2 months. We report a case of a girl with severe neurodevelopmental delay associated with a small short arm interstitial deletion of chromosome 2, 46,XX, del(2)(p14p15). Two reported cases with larger interstitial deletions overlapping the segment $2 \mathrm{p} 14 \mathrm{p} 15$ are reviewed for comparison. ${ }^{8}{ }^{13}$

The proband, a 30 month old girl, was born at term by spontaneous vaginal delivery with Apgar scores of 9 and 9 at one and five minutes, respectively. The mother was gravida 2, para 1 . The first child is a normal, healthy, 5 year old girl. The pregnancy was uneventful. At the birth of the proband, the mother and father were aged 22 and 27 years, respectively. The parents were consanguineous and of Arabic origin. Both parents were phenotypically normal. There was no known family history of congenital anomalies or mental retardation.

At birth, the proband had a weight of $3180 \mathrm{~g}$ (50th centile) and a length of $47 \mathrm{~cm}$ (25th centile) and presented with microcephaly and a head circumference of $30 \mathrm{~cm}$ $(<5$ th centile). Dysmorphic features noted at birth were abnormal sloping of the forehead, hypertelorism, micrognathia, bulbous nose, thin lips, long, shallow philtrum, widely spaced nipples, a single simian crease on the left hand, long halluces, and bilateral talipes equinovarus (fig 1). Ophthalmological examination showed normal bilateral eye segments. Both fundi appeared incurved with no angulation, which is a normal eye variant. Inborn errors of metabolism screening (tandem MS test) for amino acids, urea cycle defects, and organic acidosis was normal. Serum ammonia and lactic acid were within normal limits. MRI scan of the brain showed normal intracranial structures. During early infancy, the proband had gastro-oesophageal reflux that cycle defects, required medical therapy. Clinical evaluation at 7 months of age showed that the head growth was very slow and continued to be below the 5th centile (head circumference $36 \mathrm{~cm}$ ). Physical growth was also retarded with a poor weight gain (weight $5.8 \mathrm{~kg}$ and length $61 \mathrm{~cm}$, both <5th centile). The baby also showed marked developmental delay. She could not sit, roll over, reach for objects, transfer objects from one hand to the other, or follow moving objects. She showed significant axial hypotonia with spasticity in all limbs. Follow up of the patient at 30 months of age showed severe microcephaly (head circumference $39.5 \mathrm{~cm},<5$ th centile) and growth delay (weight $8.3 \mathrm{~kg}$ and length $78 \mathrm{~cm}$, both $<5$ th centile). She was spastic with generalised hyperreflexia. There were no seizures. Her right sided hearing was impaired owing to conductive

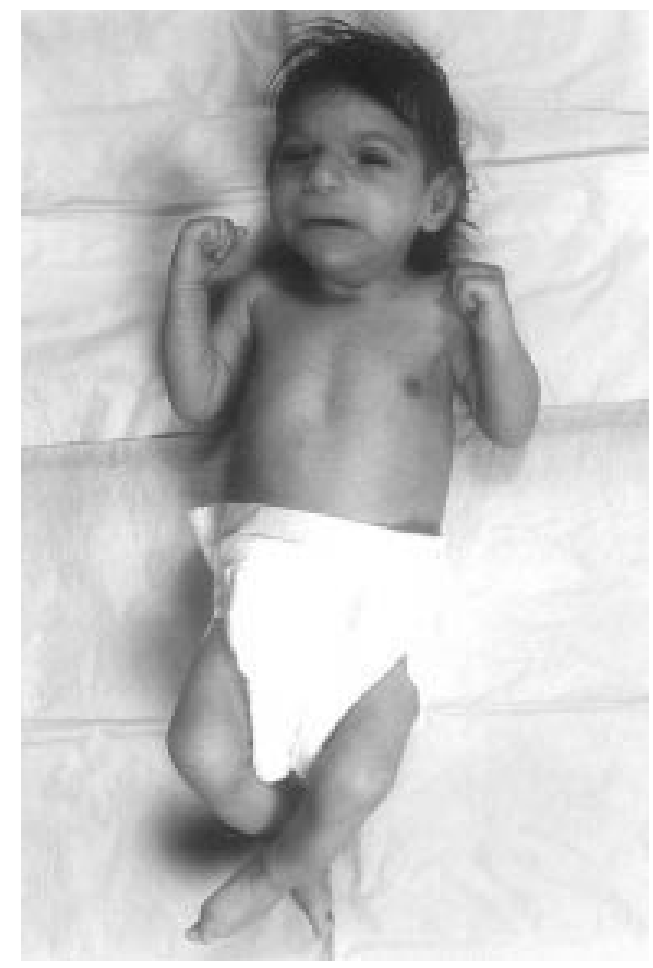

Figure 1 The proband at the age of 70 days.

deafness caused by chronic suppurative otitis media. She had bilateral decrease of visual acuity and left exotropia but no nystagmus. She started to sit without support by 28 months of age, but could not stand, walk, or talk.

Chromosomal studies on peripheral lymphocyte cultures showed a small interstitial deletion in the short arm of one homologue of chromosome 2, 46,XX, del(2)(p14p15), in all 20 cells examined. The breakpoints of the deleted segment were determined by standard GTG banding at a high banding resolution (>850 banding level, fig 2 ). This deletion was concluded to be de novo since blood karyotypes of the parents were normal. To investigate whether or not other chromosomes were involved in this abnormality, fluorescence in situ hybridisation (FISH) using a painting probe specific for the whole of chromosome 2 was performed. The painting probe hybridised to the entire length of both homologues of chromosome 2 . There was no hybridisation signal from any other chromosome.

To our knowledge there are two published cases that report pure $2 p$ deletions encompassing bands p14-p15. However, in both of these cases the $2 p$ deletion was larger than in our patient and encompassed other adjacent bands. The first case reported from Belgium by Fryns et al was a boy who had a deletion of the segment 2 p11p21 and an extra small acentric fragment. The acentric fragment has been found by fluorescence in situ hybridisation (FISH) to be derived from the deleted $2 \mathrm{p}$ segment. ${ }^{13}$ Consequently, this patient does not have full monosomy for $2 \mathrm{p} 11 \mathrm{p} 21$ and monosomy for the segment $2 \mathrm{p} 14 \mathrm{p} 15$ cannot be ascertained. Therefore, comparison between this case and ours should be treated with caution. The second case reported from Romania by Duca et al ${ }^{9}$ was a girl who had a deletion of segment $2 \mathrm{p} 13 \mathrm{p} 15$. The second patient therefore had 


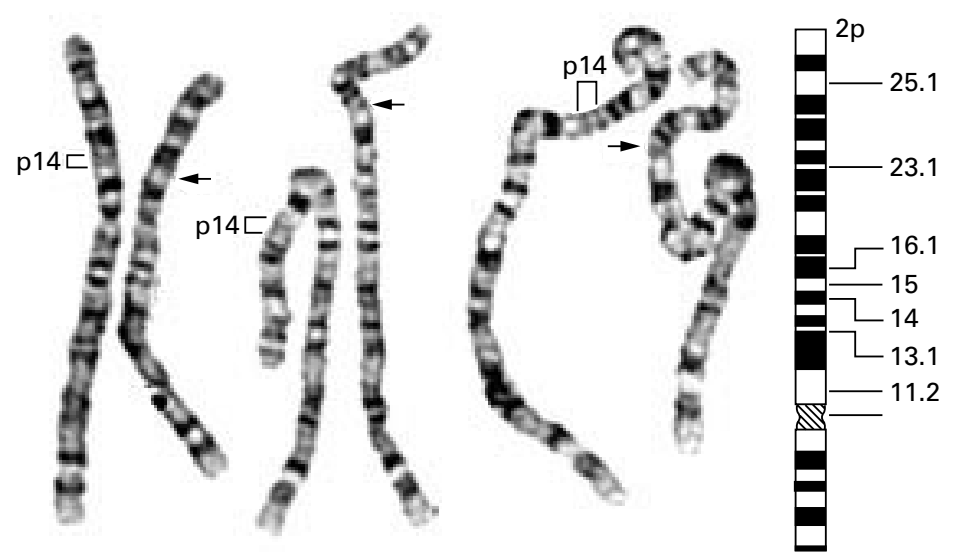

Figure 2 Chromosome 2 composite karyotypes of the proband. The arrows point to the deleted region of chromosome 2. At high banding resolution, band $2 p 14$ resolves into two bands of which the top one is apparently deleted.

monosomy for the segment $2 \mathrm{p} 14 \mathrm{p} 15$ as is the case in our patient. Clinical findings of these two cases and the present case are listed in table 1 for comparison. As indicated in table 1, many clinical features of our patient have also been reported in one or both of the other two patients. These include psychomotor retardation, growth delay, feeding difficulties, abnormal facial features, widely spaced nipples, long halluces, axial hypotonia, and limb spasticity. Chest and spine anomalies, which are reported in the other two cases, are not present in our patient but may develop at a later stage. Of the anomalies found in our patient and not reported in the other two cases, microcephaly is the major one. Microcephaly was also not reported in three other cases with proximal $2 \mathrm{p}$ deletions within region $2 \mathrm{p} 11.2 \mathrm{p} 13 .{ }^{10-12}$ Microcephaly, however, has been reported in cases with more distal chromosome $2 \mathrm{p}$ deletions within the region $2 \mathrm{p} 21$ to 2 pter. $^{1-7}$

The association in our patient of a small chromosomal deletion, which involved two chromosomal bands, with dysmorphic features, axial hypotonia, spasticity, microcephaly, and developmental delay is suggestive of a contiguous (microdeletion) gene syndrome. Contiguous gene deletions cause dysmorphic features, organ malformations, and mental deficiency by haploinsufficiency,

Table 1 Clinical findings of cases with comparable $2 p$ deletions

\begin{tabular}{|c|c|c|c|}
\hline & Fryns et al ${ }^{4}$ & Duca et $a l^{l}$ & Present case \\
\hline \multicolumn{4}{|l|}{ General } \\
\hline Deleted segment & $\begin{array}{l}\mathrm{p} 11 \mathrm{p} 21 \\
+ \text { Acentric fragment }\end{array}$ & p13p15 & p14p15 \\
\hline Sex & Male & Female & Female \\
\hline Maternal age at birth & 25 & 30 & 22 \\
\hline Paternal age at birth & 44 & 29 & 27 \\
\hline Consanguinity of parents & - & - & + \\
\hline Age at report & $14 \mathrm{y}$ & $5 y$ & $30 \mathrm{mth}$ \\
\hline Ethnic origin & Belgian & Romanian & Arabic \\
\hline \multicolumn{4}{|l|}{ Growth and development } \\
\hline Growth delay & - & + & + \\
\hline Psychomotor retardation & + & + & + \\
\hline Feeding difficulties & + & ? & + \\
\hline Hypotonia & $+($ ?axial $)$ & ? & $+($ axial $)$ \\
\hline Spasticity of limbs & + & ? & + \\
\hline \multicolumn{4}{|l|}{ Head, face, and neck } \\
\hline Microcephaly & - & - & + \\
\hline Frontal and parietal bossing & - & + & - \\
\hline Narrow forehead & + & + & - \\
\hline Abnormal sloping forehead & - & - & + \\
\hline Asymmetrical face & - & + & - \\
\hline Horizontal palpebral fissures & _- & + & _- \\
\hline Hypertelorism & - & - & + \\
\hline Low set ears & - & + & - \\
\hline Strabismus & + & + & + \\
\hline Abnormal pigmentation of iris & + & - & - \\
\hline Enophthalmos & - & + & _- \\
\hline Sloping fundi & - & - & + \\
\hline Impaired vision & - & - & + \\
\hline Bulbous nose & - & - & + \\
\hline Philtrum & - & Short & Long, shallow \\
\hline Thin lips & _- & - & + \\
\hline Fish mouth & - & + & + \\
\hline Micrognathia & - & - & + \\
\hline Short neck & + & + & - \\
\hline \multicolumn{4}{|l|}{ Chest and spine } \\
\hline Chest & Long, narrow & $\begin{array}{l}\text { Wide based thorax with thickened } \\
\text { ribs and sternum excavatum }\end{array}$ & Currently no anomalies seen \\
\hline Widely spaced nipples & - & + & + \\
\hline Spine & Kyphosis & Dorsal left concave kyphoscoliosis & Currently no anomalies seen \\
\hline \multicolumn{4}{|c|}{ 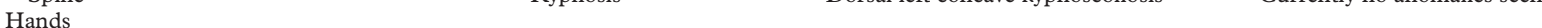 } \\
\hline Simian crease & - & - & + \\
\hline \multicolumn{4}{|l|}{ Feet } \\
\hline Club feet & - & - & + \\
\hline Long halluces & + & + & + \\
\hline Overlapping toes & - & + & - \\
\hline
\end{tabular}


deletion of imprinted genes, and unmasking of recessive mutations. Unmasking of recessive mutations is inevitably more relevant to our patient, who has consanguineous parents, than to the two patients reported by Duca et al ${ }^{9}$ and Fryns et $a l^{8}{ }^{8}$ who have non-consanguineous parents. Consanguineous parents are more likely to share similar genes in the heterozygous form than non-consanguineous ones and this increases the probability of unmasking recessive mutations in their offspring in the event of a chromosomal deletion. The unmasking of deleterious recessive mutations may have increased the severity of neurodevelopmental delay in our patient and resulted in microcephaly, which is not present in the two patients reported by Duca et al ${ }^{9}$ and Fryns et $a l^{8}{ }^{8}$ It is also possible that our patient may have an independently inherited autosomal recessive disorder that caused or contributed to the severity of the phenotypic features. One of these disorders is autosomal recessive microcephaly that has been reported to be common among Arabs. ${ }^{14}{ }^{15}$ Molecular DNA family studies may help to clarify whether or not the chromosomal deletion per se was responsible for all or some the phenotypic malformations of the patient. They will also be useful in defining the extent of the chromosomal deletion and the parent of origin.

We are grateful to Mr Kim Genereux, Department of Pathology, King Fahad National Guard Hospital, Riyadh, for his photographic assistance.

ISAM M AMIR* KHALIL I AL-TAWIL $†$ MUNEEF M AL-HATHAL

*Department of Pathology, King Fahad National Guard Hospital, PO Box 22490, Riyadh 11426, Saudi Arabia †Department of Paediatrics, King Fahad National Guard Hospital, PO Box 22490, Riyadh 11426, Saudi Arabia
Correspondence to: Dr Amir, isamamir@workmail.com

1 Grundy HO, Niemeyer P, Rupani MK, Ward VF, Wassman ER. Prenatal detection of cyclopia associated with interstitial deletion of $2 \mathrm{p} . A m 7 \mathrm{Med}$ detection of cyclopia a

2 Münke M, Emanuel BS, Zackai EH. Holoprosencephaly: association with interstitial deletion of $2 \mathrm{p}$ and review of the cytogenetic literature. Am $\mathcal{F}$ Med Genet 1988;30:929-38.

3 Wilson WG, Shanks DE, Sudduth KW, Couper KA, McIlhenny J. Holoprosencephaly and interstitial deletion of 2(p2101p2109). Am f Med Genet 1989;34:252-4

4 Francis GL, Flannery DB, Byrd JR, Fisher ST. An apparent de novo terminal deletion of chromosome 2 (pter $\rightarrow$ p24:). 7 Med Genet 1990;27:137-8.

5 Neidich J, Zackai E, Aronson M, Emanuel BS. Deletion 2p: a cytogenetic and clinical update. Am F Med Genet 1987;27:707-10.

6 Penchaszadeh VB, Dowling PK, Davis JG, Schmidt R, Wapnir RA. Interstitial deletion of chromosome 2 (p23p25). Am f Med Genet 1987;27:701-6.

7 Saal HM, King LJ, Zimmerman D, Johnson RC, Carr AG, SamangoSprouse CA, Stanley W. Loss of the n-myc oncogene in a patient with a small interstitial deletion of the short arm of chromosome 2. Am f Med Genet 1996;66:373-7.

8 Fryns JP, De Waele P, Van Den Berghe H. Interstitial deletion of the short arm of chromosome 2 in a moderately mentally retarded boy without gross clinical stigmata. Hum Genet 1979;51:123-5.

9 Duca D, Ioan D, Meila P, Ionescu-Cerna M, Simionescu L, Maximilian C. Interstitial deletion (2)(p13p15). Hum Genet 1981;57:214-16.

10 Prasher VP, Krishnan VH, Klarke DJ, Maliszewska CT, Corbett JA. Deletion of chromosome 2 (p11-p13): case report and review. F Med Genet 1993;30:604-6.

11 Los FJ, Van Hemel JO, Jacobs HJ, Drop SL, Van Dongen JJ. De novo deletion (2)(p11.2p13): clinical, cytogenetic, and immunological data. $\mathcal{F}$ Med tion (2)(p11.2p13):

12 Wenger SL, McPherson EW. Interstitial deletion 2(p11.2p13): a rare chromosomal abnormality. Clin Genet 1997;52:61-2.

13 Petit P, Fryns JP. Interstitial deletion $2 \mathrm{p}$ accompanied by marker chromosome formation of the deleted segment resulting in a stable acentric marker chromosome. Genet Couns 1997;8:341-3.

14 Farag TI, Al-Awadi SA, El-Badramany MH, Aref MA, Kasrawi B, KrishnaMurthy DS, El-Khalifa MY, Yadav G, Marafie MJ, Bastaki L, Wahba RA, Mohammed FM, Abul Hassan S, Redha AA, Redha MA, Al-Aboud H, Al-Hijii S, Al-Dighashem D, Al-Hashash N, Al-Jeryan L, Al-Khorafi $\mathrm{H}$, Ourban EA, Al-Sulaiman I. Disease profile of 400 institutionalized mentally retarded patients in Kuwait. Clin Genet 1993;44:329-34.

15 Teebi AS, Al-Awadi SA, White AG. Autosomal recessive microcephaly with normal intelligence. Am F Med Genet 1987;26:355-9. 